\title{
Ecto-Nucleoside Triphosphate Diphosphohydrolase Activities in Trypano- somatids: Possible Roles in Infection, Virulence and Purine Recycling
}

\author{
José Roberto Meyer-Fernandes*, ${ }^{*}$, Daniela Cosentino-Gomes ${ }^{1}$, Danielle Pereira Vieira ${ }^{2}$ and Angela \\ Hampshire Lopes ${ }^{2}$
}

\author{
${ }^{1}$ Instituto de Bioquímica Médica, UFRJ, Cidade Universitária, Ilha do Fundão, Rio de Janeiro, R.J. 21941-590, Brazil \\ ${ }^{2}$ Instituto de Microbiologia Prof. Paulo de Góes, UFRJ, Cidade Universitária, Ilha do Fundão, Rio de Janeiro, R.J. \\ 21941-590, Brazil
}

\begin{abstract}
Ecto-nucleoside triphosphate diphosphohydrolases (ecto-NTPDases), also known as ecto-ATPases and/or ectoapyrases, are integral membrane glycoproteins or soluble enzymes that are dependent on divalent cations. These ectoenzymes are important ecto-nucleotidases that are characterized by the ability to hydrolyze nucleoside triphosphates and nucleoside diphosphates to the monophosphate form. The hydrolysis of nucleoside monophosphates to nucleosides such as adenosine may then be catalyzed by the action of ecto-5'nucleotidases. The present study reviews the sequential hydrolysis of ATP $\rightarrow$ ADP $\rightarrow$ AMP $\rightarrow$ adenosine catalyzed by these ecto-enzymes from different trypanosomatids. These reactions participate in the salvage of purines in these parasites and simultaneously interfere with the establishment of infection and changes in the host immune response.
\end{abstract}

Keywords: Ecto-nucleoside triphosphate diphosphohydrolases, trypanosomatids, virulence, adenosine acquisition.

Surface membrane interactions between parasites and their host cells are of critical importance for the survival of the parasite, from both immunological and physiological viewpoints [1-4]. Plasma membranes of cells may contain enzymes that are oriented with their active sites facing the external medium rather than the cytoplasm. The activities of these enzymes can be measured using living cells [5-8]. Ecto-nucleoside triphosphate diphosphohydrolases are glycoproteins present in the plasma membrane with their active sites facing the external environment, which suggests that these enzymes may be involved in surface membrane interactions between parasites and their host cells. Ectonucleoside triphosphate diphosphohydrolases have been described in several protozoa parasites including Toxoplasma gondii [9-15], Tetrahymena thermophila [16], Leishmania sp, [17-25], Entamoeba histolytica [26], Acanthamoeba sp [27], Balamuthia mandrillaris [28], Trichomonas vaginalis [29-31], Trichomonas foetus [32], Trichomonas gallinae [33], Giardia lamblia [34], Crithidia deanei [35], Herpetomonas sp [36, 37] and Trypanosoma sp [38-44]. These enzymes are divalent cation-dependent. In trypanosomatide parasites such as Leishmania tropica [21], Leishmania amazonensis [20], Crithidia deanei [35], Trypanosoma cruzi [40] and Trypanosoma rangeli [39], the ecto-ATPase activities are stimulated by magnesium and manganese, but not by calcium $[20,21,40]$. In Trypanosoma brucei the ectoATPase activity is stimulated by magnesium and manganese, and also by calcium and zinc [38]. The ecto-nucleoside triphosphate diphosphohydrolases from trypanosomatids are

*Address correspondence to this author at the Instituto de Bioquímica Médica, UFRJ, Cidade Universitária, Ilha do Fundão, Rio de Janeiro, R.J. 21941-590, Brazil; Tel: + 55-21-2562-6781; Fax: +55-21-2270-5988: E-mail: meyer@bioqmed.ufrj.br membrane bound enzymes and do not secreted enzymes as observed in the apicomplexan parasite, Toxoplasma gondii [13].

Trypanosomatids are protozoan parasites that cannot synthesize purines de novo [20, 38, 45]. It has been postulated that these ecto-nucleoside triphosphate diphosphohydrolases could play a role in the salvage of purines from the host in Leishmania amazonensis [18, 20], Trypanosoma cruzi [40] and Trypanosoma brucei [38]. The ability of these trypanosomatids to hydrolyze ATP, ADP and AMP to generate adenosine (Fig. 1) was confirmed by HPLC analyses [18, 38]. It has also been demonstrated that when these protozoa are grown in the presence of adenosine, they have lower ectoATPase activity than in the absence of adenosine $[18,20,35$, 38]. This negative modulation of the ecto-ATPase activity is associated with the lower expression of the enzyme, as confirmed by flow cytometry analysis of Leishmania amazonensis incubated with different anti-NTPDase antibodies [18]. In Trypanosoma brucei, it was recently shown that the ENTPDase and ecto-5'nucleotidase activities sequentially dephosphorylate ATP to adenosine: ATP $\rightarrow$ ADP $\rightarrow$ AMP $\rightarrow$ adenosine, making adenosine available to T. brucei [38]. The inhibition of E-NTPDase activity but not the ecto5'nucleotidase activity by ferrous iron and heme suggests that E-NTPDase catalyzes the rate-limiting step in the generation of adenosine from ATP in this protozoa [46].

In trypanosomatids, the localization of ectoATPases in the plasma membrane with their active sites facing the external environment suggests that these enzymes may be involved in virulence and infection [47,48]. Interestingly, exogenous carbohydrates involved with cellular recognition and adhesion of these parasites with their hosts stimulated ecto-ATPase activities from different trypanosomatids. 


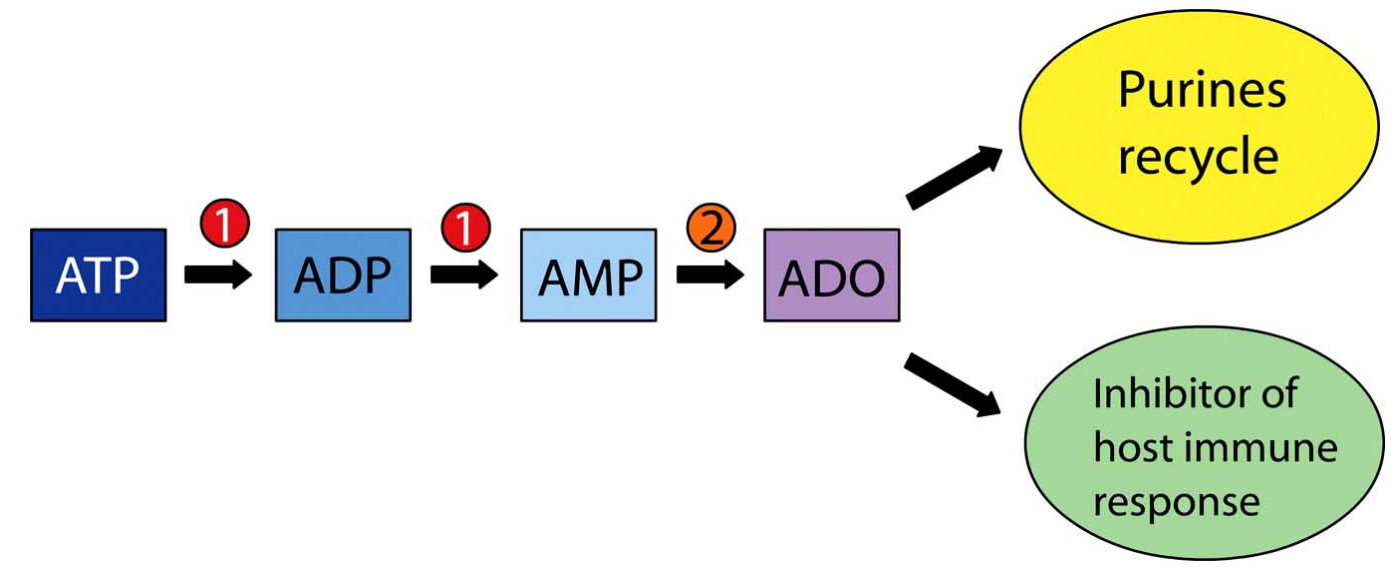

Fig. (1). Partial reactions catalyzed by ecto-nucleoside triphosphate diphosphohydrolase (1) and ecto-5'nucleotidase (2). Extracellular ATP can originate from stressed or injured cells. This mechanism triggers the host inflammatory and immune response. NTPDase of parasites modulate the level of extracellular nucleotides by the sequential hydrolysis of ATP to AMP. AMP is then dephosphorylated by the action of an ecto-5'-nucleotidase to release adenosine (ADO). Adenosine may be used in the salvage of purines or as a mediator of immune suppression by the parasites.

Galactose was a good activator of $T$. cruzi ecto-ATPase [40] while fructose was a good activator of $T$. rangeli ectoATPase [39]. Similar findings were also observed with other protozoan parasites: galactose stimulated ecto-ATPase from Entamoeba histolytica [26], Tritrichomonas foetus [32], Trichomonas vaginalis [31], and Balamuthia mandrilaris [28] while mannose stimulated the ecto-ATPase from Acanthamoeba [27]. Many other studies have shown the participation of ecto-ATPases from trypanosomatids parasites in the infection of the host cells. Ecto-ATPase activity is higher in the infective forms of $T$. cruzi (trypomastigote) than in noninfective forms (epimastigotes) [40, 41, 43]. Suramin and 4,4'diisothiocyanostylbene 2,2'-disulfonic acid, inhibitors of the $T$. cruzi ecto-ATPase, reduced the number of parasites attaching to mouse peritoneal macrophages [41]. ATP, the substrate for these enzymes, protected T. cruzi ecto-ATPase activity from inhibition by suramin and 4,4'diisothiocyanostylbene 2,2'-disulfonic acid [40], increasing parasite-infected macrophages [41]. Recently, it was also shown that suramin and other inhibitors of $T$. cruzi ectoATPase activity also promoted a marked inhibition of trypomastigotes infectivity [44]. Mice infected with ectoATPase-inhibited trypomastigotes had lower levels of parasitemia and higher host survival than non-inhibited control parasites [44]. In Leishmania amazonensis, ecto-ATPase activity was also higher in the amastigote stage than in axenic promastigotes [18]. The ecto-ATPase activity of $L$. amazonensis was increased when the parasites were submitted to heat shock [17], which may play a fundamental role in parasites during infection [17]. In species of the genus Leishmania, further evidence for a role of ecto-ATPase in virulence comes from the observation that pretreatment of the parasites with anti-NTPDase antibodies reduced the interaction of the promastigotes with mouse peritoneal macrophages [18].

The ecto-nucleoside triphosphate diphosphohydrolases could also play a role in modulating inflammation and the immune response by affecting the extracellular concentration of ATP [22]. ATP, released in the extracellular milieu by injured or pathogen-stimulated cells, participates in many aspects of the establishment of an inflammatory response such as cytokine secretion and cellular migration [22, 47]. The presence of ecto-ATPases and ecto-5'nucleotidases in trypanosomatids suggests the possibility that the coordinated action of these enzymes on extracellular ATP hydrolysis and adenosine production could interfere with the immune response of the host (Fig. 1). It has been demonstrated that the presence of increased levels of adenosine early in infection by Leishmania braziliensis causes an increase in lesion size and parasitism and delayed lesion control [22]. However, it is not yet clear whether only the increase of extracellular adenosine concentration and/or a decrease of ATP concentrations are involved in Leishmania infection. Studies on the selective inhibition by ferrous iron and heme of E-NTPDase and ecto-5'nucleotidase activities from $T$. brucei [46] could clarify the role of extracellular ATP and adenosine in several infectious diseases involving Trypanosomatids, opening new perspectives for rational drug design.

\section{ACKNOWLEDGEMENTS}

These studies were supported by grants from the Brazilian Agencies Conselho Nacional de Desenvolvimento Científico e Tecnológico (CNPq), Coordenação de Aperfeiçoamento de Pessoal de Nível Superior (CAPES) and Fundação de Amparo à Pesquisa do Estado do Rio de Janeiro (FAPERJ).

\section{REFERENCES}

[1] Alexander J, Russel DG. The interaction of Leishmania species with macrophages. Adv Parasitol 1992; 31: 175-254.

[2] Vannier-Santos MA, Martiny A, Meyer-Fernandes JR, De Souza W. Leishmanial protein kinase $\mathrm{C}$ may regulate parasite infection via secreted acid phosphatase. Eur J Cell Biol 1995; 67: 112-9.

[3] Martiny A, Vannier-Santos MA, Borges VM, et al. Leishmania induced tyrosine phosphorylation in the host macrophage and its implication to infection. Eur J Cell Biol 1996; 71: 206-15.

[4] Martiny A, Meyer-Fernandes JR, De Souza W, Vannier-Santos MA. Altered tyrosine phosphorylation of ERK1 MAP kinase and other macrophage molecules caused by Leishmania amastigotes. Mol Biochem Parasitol 1999; 102: 1-12

[5] Cosentino-Gomes D, Russo-Abrahão T, Fonseca-de-Souza AL, Ferreira CR, Galina A, Meyer-Fernandes JR. Modulation of Trypanosoma rangeli ecto-phosphatase activity by hydrogen peroxide. Free Radic Biol Med 2009; 47: 152-8. 
[6] Fonseca-de-Souza AL, Dick CF, dos Santos ALA, Fonseca FV, Meyer-Fernandes JR. Trypanosoma rangeli: a possible role for ecto-phosphatase activity on cell proliferation. Exp Parasitol 2009; 122: 242-6.

[7] Amazonas JN, Cosentino-Gomes D, Werneck-Lacerda A, et al. Giardia lamblia: Characterization of ecto-phosphatase activities. Exp Parasitol 2009; 121: 15-21

[8] Pinheiro AAD, Amazonas JN, Barros FD, et al. Entamoeba histolytica: an ecto-phosphatase activity regulated by oxidationreduction reactions. Exp Parasitol 2007; 115: 352-8.

[9] Gherardi A, Sarciron ME. Molecules targeting the purine salvage pathway in Apicomplexan parasites. Trends Parasitol 2007; 23: 384-9.

[10] Asai T, Miura S, Sibley LD, Okabayashi H, Takeuchi T. Bochemical and molecular characterization of nucleoside triphosphate hydrolase isozymes from the parasitic protozoan Toxoplasma gondii. J Biol Chem 1995; 270: 11391-7.

[11] Asai T, O'Sullivan WJ, Tatibana M. A potent nucleoside triphosphate hydrolase from the parasitic protozoan Toxoplasma gondii. Purification, some properties, and activation by thiol compounds. J Biol Chem 1983; 258: 6816-22.

[12] Bermudes D, Peck KR, Afifi MA, Beckers CJ, Joiner KA. Tandemly repeated genes encode nucleoside triphosphate hydrolase isoforms secreted into the parasitophorous vacuole of Toxoplasma gondii. J Biol Chem 1994; 269: 29252-60.

[13] Sibley LD, Niesman IR, Asai T, Takeuchi T. Toxoplasma gondii: secretion of a potent nucleoside triphosphate hydrolase into the parasitophorous vacuole. Exp Parasitol 1994;79: 301-11.

[14] Nakaar V, Beckers CJ, Polotsky V, Joiner KA. Basis for substrate specificity of the Toxoplasma gondii nucleoside triphosphate hydrolase. Mol Biochem Parasitol 1998; 97: 209-20.

[15] Ngô HM, Ngo EO, Bzik DJ, Joiner KA. Toxoplasma gondii: are host cell adenosine nucleotides a direct source for purine salvage? Exp Parasitol 2000; 95: 148-53

[16] Smith TM Jr, Kirley TL, Hennessey TM. A soluble ecto-ATPase from Tetrahymena thermophila: purification and similarity to the membrane-bound ecto-ATPase of smooth muscle. Arch Biochem Biophys 1997; 337: 351-9.

[17] Peres-Sampaio CE, de Almeida-Amaral EE, Giarola NLL, MeyerFernandes JR. Leishmania amazonensis: effects of heat shock on ecto-ATPase activity. Exp Parasitol 2008; 119: 135-43.

[18] Pinheiro CM, Martins-Duarte ES, Ferraro RB , et al. Leishmania amazonensis: Biological and biochemical characterization of ectonucleoside triphosphate diphosphohydrolase activities. Exp Parasitol 2006; 114: 16-25.

[19] Peres-Sampaio CE, Palumbo ST, Meyer-Fernandes JR. An ectoATPase activity present in Leishmania tropica stimulated by dextran sulfate. Z Naturforsch C 2001; 56: 820-5.

[20] Berrêdo-Pinho M, Peres-Sampaio CE, Chrispim PPM, et al. A Mgdependent ecto-ATPase in Leishmania amazonensis and its possible role in adenosine acquisition and virulence. Arch Biochem Biophys 2001; 391: 16-24.

[21] Meyer-Fernandes JR, Dutra PM, Rodrigues CO, SaadNehme J, Lopes AHCS. Mg-dependent ecto-ATPase activity in Leishmania tropica. Arch Biochem Biophys 1997; 341: 40-6.

[22] de Almeida Marques-da-Silva E, de Oliveira JC, Figueiredo AB, et al. Extracellular nucleotide metabolism in Leishmania: influence of adenosine in the establishment of infection. Microbes Infect 2008; 10: 850-7.

[23] Coimbra ES, Gonçalves-da-Costa SC, Corte-Real S, et al. Characterization and cytochemical localization of na ATP diphosphohydrolase from Leishmania amazonensis promastigotes. Parasitology 2002; 124: 137-43.

[24] Coimbra ES, Gonçalves-da-Costa SC, Costa BL, et al. A Leishmania (L.) amazonensis ATP diphosphohydrolase isoform and potato apyrase share epitopes: antigenicity and correlation with disease progression. Parasitology 2008; 135: 327-35.

[25] Faria-Pinto P, Rezende-Soares FA, Molica AM, et al. Mapping of the conserved antigenic domains shared between potato apyrase and parasite ATP diphosphohydrolases: potential application in human parasitic diseases. Parasitology 2008; 135: 943-53.
[26] Barros FS, De Menezes LF, Pinheiro AAS, et al. Ectonucleotide diphosphohydrolase activities in Entamoeba histolytica. Arch Biochem Biophys 2000; 375: 304-14.

[27] Sissons J, Alsam S, Jayasekera S, Khan NA. Ecto-ATPase of clinical and non-clinical isolates of Acanthamoeba. Microb Pathog 2004; 37: 231-9.

[28] Matin A, Khan NA. Demonstration and partial characterization of ecto-ATPase in Balamuthia mandrillaris and its possible role in the host-cell interactions. Lett Appl Microbiol 2008; 47: 348-54.

[29] De Jesus JB, Ferreira MA, Cuervo P, Britto C, e Silva-Filho FCE, Meyer-Fernandes JR. Iron modulates ecto-phosphohydrolase activities in pathogenic trichomonads. Parasitol Int 2006; 55: 285-90.

[30] Tasca T, Bonan CD, De Carli GA, Sarkis JJ. Trichomonas vaginalis: cytochemical localization of a NTPDase1 and na ecto-5'nucleotidase and effects of adenine nucleotides on cellular viability. Parasitol Res 2004; 93: 300-3

[31] de Jesus JB, Pinheiro AAD, Lopes AHCS, Meyer-Fernandes JR. An ectonucleotide ATP-diphosphohydrolase activity in Trichomonas vaginalis stimulated by galactose and its possible role in virulence. Z Naturforsch C 2002; 57: 890-6.

[32] Jesus JB, Lopes AHCS, Meyer-Fernandes JR. Characterization of an ecto-ATPase of Trichomonas foetus. Vet Parasitol 2002; 103: $29-42$.

[33] Borges FP, de Brum VP, Wiltuschnig RC, Tasca T, De Carli GA, Bonan CD. Characterization of nucleoside triphosphate diphosphohydrolase activity in Trichomonas gallinae and the influence of penicillin and streptomycin in extracellular nucleotide hydrolisis. FEMS Microbiol Lett 2008; 283: 189-95.

[34] Pinheiro AAD, Cosentino-Gomes D, Lanfredi-Rangel A, Ferraro RB, De Souza W, Meyer-Fernandes JR. Giardia lamblia: biochemical characterization of an ecto-ATPase activity. Exp Parasitol 2008; 119: 279-84.

[35] Lemos AD, Pinheiro AAD, de Berrêdo-Pinho M, et al. Ectonucleotide diphosphohydrolase activity in Crithidia deanei. Parasitol Res 2002; 88: 905-11.

[36] Moreira OC, Rios PF, Esteves FF, Meyer-Fernandes JR, Barrabin H. CrATP as a new inhibitor of ecto-ATPase of trypanosomatids. Parasitology 2009; 136: 35-44.

[37] Alves-Ferreira M, Dutra PML, Lopes AHCS, Ferreira-Pereira A, Scofano HM, Meyer-Fernandes JR. Magnesium-dependent ectoATP diphosphohydrolase activity in Herpetomonas muscarum muscarum. Curr Microbiol 2003; 47: 265-71.

[38] Leite MDS, Thomaz R, Fonseca FV, Panizzutti R, Vercesi AE, Meyer-Fernandes JR. Trypanosoma brucei brucei: biochemical characterization of ecto-nucleoside triphosphate diphosphohydrolase activities. Exp Parasitol 2007; 115: 315-23.

[39] Fonseca FV, de Souza ALF, Mariano AC, Entringer PF, Gondim KC, Meyer-Fernandes JR. Trypanosoma rangeli: characterization of a Mg-dependent ecto-ATP-diphosphohydrolase activity. Exp Parasitol 2006;112: 76-84.

[40] Meyer-Fernandes JR, Saad-Nehme J, Peres-Sampaio CE, et al. A $\mathrm{Mg}$-dependent ecto-ATPase is increased in the infective stages of Trypanosoma cruzi. Parasitol Res 2004; 93: 41-50.

[41] Bisaggio DFR, Peres-Sampaio CE, Meyer-Fernandes JR, SoutoPadrón T. Ecto-ATPase activity on the surface of Trypanosoma cruzi and its possible role in the parasite-host cell interaction. Parasitol Res 2003; 91: 273-82.

[42] Bernardes CF, Meyer-Fernandes JR, Saad-Nehme J, et al. Effects of 4,4'-diisothyocyanatostilbene-2,2'-disulfonic acid on Trypanosoma cruzi proliferation and $\mathrm{Ca}(2+)$ homeostasis. Int $\mathrm{J}$ Biochem Cell Biol 2000; 32: 519-27.

[43] Fietto JL, DeMarco R, Nascimento IP, et al. Characterization and immunolocalization of an NTP diphosphohydrolase of Trypanosoma cruzi. Biochem Biophys Res Commun 2004; 316: 454-60.

[44] Santos RF, Pôssa MA, Bastos MS, et al. Influence of ectonucleoside triphosphate diphosphohydrolase activity on Trypanosoma cruzi infectivity and virulence. PLoS Negl Trop Dis 2009; 3 : e387.

[45] de Koning HP, Watson CJ, Sutcliffe L, Jarvis SM. Differential regulation of nucleoside and nucleobase transporters in Crithidia fasciculate and Trypanosoma brucei brucei. Mol Biochem Parasitol 2000; 106: 93-107. 
[46] Leite MS, Thomaz R, Oliveira JHM, Oliveira PL, MeyerFernandes JR. Trypanosoma brucei brucei: effects of ferrous iron and heme on ecto-nucleoside triphosphate diphosphohydrolase activity. Exp Parasitol 2009; 121(2):137-43.

[47] Sansom FM, Robson SC, Hartland EL. Possible effects of microbial ecto-nucleoside triphosphate diphosphohydrolases on hostpathogen interactions. Microbiol Mol Biol Rev 2008; 72: 765-81.
[48] Conceição de Souza M, de Assis EA, Gomes RS, et al. The influence of ecto-nucleotidases on Leishmania amazonensis infection and immune response in C57B/6 mice. Acta Trop 2010; 115: 262269.

Received: November 10, 2009

Revised: August 27, 2010

Accepted: August 28, 2010

(C) Meyer-Fernandes et al.; Licensee Bentham Open.

This is an open access article licensed under the terms of the Creative Commons Attribution Non-Commercial License (http://creativecommons.org/licenses/by-nc/3.0/) which permits unrestricted, non-commercial use, distribution and reproduction in any medium, provided the work is properly cited. 